\title{
Semantic Relations vs. Abstract Syntactic Relations: Evidence from Halkomelem
}

\author{
Patrick Farrell \\ University of California, Davis
}

\section{THE THEORETICAL ISSUE}

Relationally oriented theories of grammar make available essentially two approaches to paraphrases such as those in (1).

(1) a. Fred handed the towel to Wilma

b. Fred handed Wilma the towel

According to the REVALUATION approach, which characterizes RELATIONAL GRAMMAR (RG) (Perlmutter 1980, Perlmutter and Postal 1983), both sentences show the same grammatical relations at an initial level of structure. Fred is subject (or 1), Wilma indirect object (or 3), and the towel direct object (or 2). In (1b), however, Wilma and the towel bear different relations at the final level of structure. The initial 3 is said to advance to 2 , causing the initial 2 to revalue to chomeur, as shown in Figure 1.

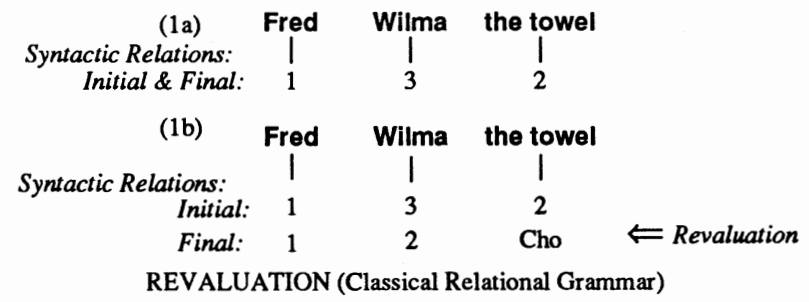

Figure 1

Theories that do not make use of revaluations and multistratal representations characterize the relationship between sentences like (1a) and (1b), in one way or another, as involving an ALTERNATIVE LINKING of the semantic arguments of a predicate with grammatical relations, as schematized in Figure 2.

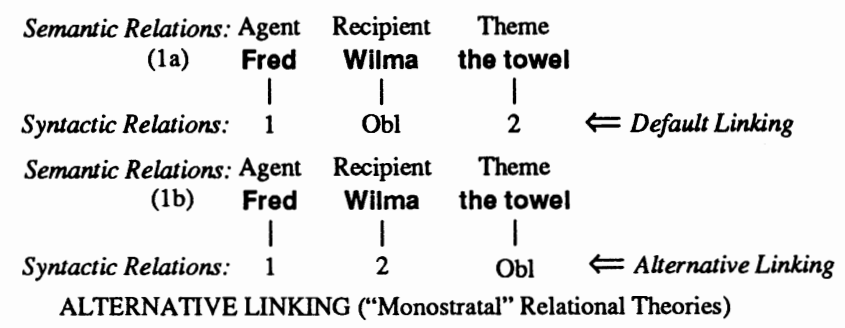

Figure 2

Which of these two devices is made available in a theory has important consequences for the question of what kinds of relations will play a role in accounting 
for grammatical phenomena. Consider, for example, the phenomenon illustrated in (2).

(2) a. Fred handed the towel to Wilma soaking wet

b. Fred handed Wilma the towel soaking wet

c. * Fred handed the towel to Wilma soaking wet

d. * Fred handed Wilma the towel soaking wet

A predicate adjective can be construed with the towel in both versions of the dative shift construction; but can be construed with Wilma in neither. If an alternative linking analysis is given, the condition must be formulated in terms of semantic relations (as in (3b)), since there is no syntactic relation shared by the towel in (1a) and (1b).

(3) a. An object oriented predicate adjective is construed with an INTTIAL 2.

b. An object oriented predicate adjective is construed with a THEME.

If a revaluation analysis is given, on the other hand, the towel is an initial 2 in both sentences and Wilma is not an initial 2 in either. The condition can be formulated without reference to notions such as THEME, as shown in (3a). A question arises as to whether there is any need to recognize semantic relations, given the possibility of multistratal representations of syntactic relations.

Taking classical RG as a starting point, in Farrell (1991) I develop and motivate a kind of relational theory in which semantic relations such as THEME and AGENT are explicitly incorporated into representations of clause structure and revaluation and alternative linking are both allowed. ${ }^{1}$ I claim that alternative linking is actually quite common and the range of revaluation constructions is considerably smaller than generally thought. By way of illustration, the kind of analysis of (1a) and (1b) that I propose is shown in Figure 3.2



Figure 3

Based on a partial reanalysis of a corpus of data from Halkomelem (Salish) analyzed from the perspective of classical RG in a series of works by Donna Gerdts, I want to argue for this latter kind of relational theory in general and, in particular, for the claim that a set of semantic relations distinct from abstract (i.e. non-final) syntactic relations must be recognized. The argumentation proceeds as follows. First, I look at four kinds of constructions for which Gerdts appeals to revaluation analyses: passive, causative, antipassive, and applicative. I argue that a subset of these - namely the latter three - are better analyzed otherwise. Based on these results, I examine certain grammatical phenomena which might have been understood in terms of initial syntactic relations, if multistratal analyses of the con- 
structions in question were available. Since they are not, however, it is necessary to formulate the relevant conditions in terms of semantic relations.

\section{FOUR CONSTRUCTIONS IN HALKOMELEM}

The Passive Construction

Passive clauses such as (4b) differ from their active paraphrases in several ways.

(4) a. ni q"al-ət-əs $\theta$ a słéni? to scé:łtən

ACTIVE

auxbake-tr-3erg det woman det salmon

'The woman baked the salmon.'

b. ni q"əl-ət-əm ?a $\theta$ a słéni? tò scé:łtən

PASSIVE

aux bake-tr-intr obl det womandet salmon

'The salmon was baked by the woman.' (G's 2a-b, p. 195)

First, the logical subject is marked with the general oblique case marker used for clausal dependents that are not final $1 \mathrm{~s}$ or $2 \mathrm{~s}$. Second, the ergative agreement marker found in finally transitive clauses is not present, indicating final intransitivity. Third, the general intransitive marker -om is suffixed to the verb. Fourth, as Gerdts (1988, Ch. 5) shows, the logical subject does not, in general, have the syntactic properties of a final subject, being unable, for example, to be "extracted" using the ordinary final 1 strategy in (pseudo)cleft, relative clause, and question constructions. All of these facts could be accounted for equally well under either of the analyses shown in Figure 4.

(4a)

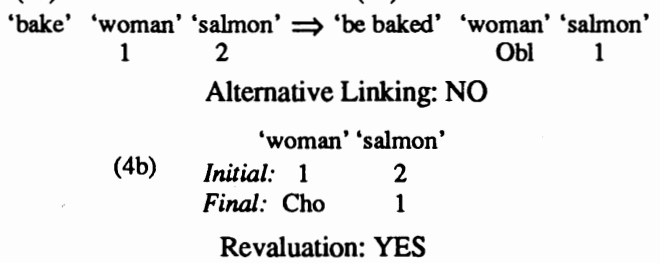

Figure 4

There is, however, at least one kind of compelling evidence for a revaluation analysis. Gerdts shows that either the logical subject or the logical object of a passive clause can "raise to object" - something which otherwise only final 1s can do. ${ }^{3}$ The sentences in (5) illustrate the phenomenon of raising to object.
a. Pi con x̌éc-t [?u Pi?-əs aux 1 subjwonder-tr lnk aux-3Ssubj do
'I wonder what the white men will do.'
cəlk"stá?mət to’ $\mathrm{x}^{\mathrm{w}}$ 'ələnítəm] det white men

 'I wonder what the white men will do.'(G's 34a-b, p. 207)

In (5b) the final 1 of the clause embedded under the verb $x^{2} c$ - is a constituent of the main clause, in which it functions as the final 2.4 (6) shows that the final 2 of the embedded clause cannot be a raisee. The sentences in (7) show the logical object and the logical subject of a passive embedded clause as raisees. 
(6) * ?i con শ̌e?x̌cí-t $\mathbf{k}^{\mathbf{*}} \theta \mathbf{u}$ nił [?u ni:n

*FINAL 2

aux lsubj wonder-tr det 3emph lnk aux-1Ssubj

cə? X'əwวł lóm-nəx"]

fut again see-l.c.tr

'I wonder if I will see that one again.' (G's 38b, p. 209)

(7)
a. ni cən x̌éc-t $\mathbf{k}^{\prime \prime} \theta \mathbf{u}$ níł [?u Pi?-əs
aux 1 subj wonder-tr det 3emph lnk aux-3Ssubj
c'éw-วt-əm ?a- $\chi$ ' John]
help-tr-intr obl-det John (G's 41b, p. 210)
'I figured out that that one was helped by John.'

LOGICAL

OBJECT

b. ni cən x̌éc-t k"0ə John [?u ?i?-əs

aux Isubj wonder-tr det John lnk aux-3Ssubj

c'éw-วt-əm k"'0u níl]

help-tr-intr det 3emph (G's 45b, p. 211)

'I figured out that that one was helped by John.'

There is no feature - whether syntactic or semantic - that would unite the raisees into a class under an alternative linking analysis of passive. Under the revaluation analysis, on the other hand, the class of possible raisees consists of nominals that are a subject in some stratum. The condition on raising to object can be formulated as in (8)..$^{5}$

(8) A raisee to object must be a 1.

\section{The Causative Construction}

Affixally mediated causativization in Halkomelem is illustrated by the following examples, which show that the causative suffix can be added to an intransitive base to create a transitive clause in which the argument that would otherwise be realized as the subject is realized as the direct object and an agent/causer argument is realized as the subject. ${ }^{6}$

(9) a. ni Tíməs to słéni?

INTRANSITIVE

aux walk det woman

'The woman walked.'

b. ni cən Tíməs-stəx" ta słéni?

CAUSATIVE

aux 1 subj walk-caus det woman

'I made/had/let the woman walk.' (G's 36a-b, p. 158)

In classical RG, such causative constructions are analyzed as CLAUSE UNIONS of initially biclausal structures. As illustrated in Figure 5, the final 1 of the inner clause (equivalent to the structure of (9a)) revalues to an object relation in the main clause, which is headed by the causative morpheme and has an agent/causer argument as initial 1; all other dependents of the inner clause - if there are any - also bear a relation, determined by general principles, in a non-initial stratum of the main clause (Aissen and Perlmutter 1983, Gibson and Raposo 1986). The alternative analysis that I propose is one according to which causativization is an operation on argument structure: an agent/causer argument is added and the argument of the base that would otherwise be the initial 1 bears the relation theme (in addition to whatever other semantic relation it may bear). By the default linking principles, the agent of the resulting argument structure is the initial 1, the theme is the initial 2.7 

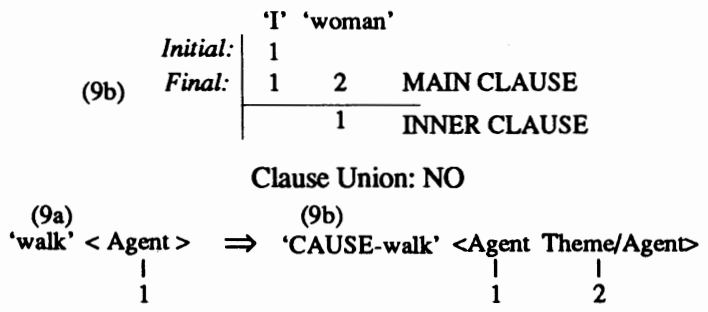

Argument Structure Manipulation: YES

Figure 5

The motivation for the proposed analysis is that it explains two otherwise mysterious restrictions on causativization. If there were an inner clause in the causative construction, one might expect that it could be transitive or passive. However, (10a) shows that, regardless of the case marking of the nominals, a transitive base cannot be causativized; (10b) shows that a passivized base cannot be causativized either.

(10) a. * ni cən q"১l-ət-stəx" (?ə) łə słéni? (?ə) k"0ə səplíl aux lsubj bake-tr-caus obl det woman obl det bread 'I had the woman bake the bread.' (based on G's 95, p. 174)

b. * ni q"כl-ət-əm-stəx"-əs $\mathrm{k}^{\mathbf{*}} \theta$ ə səplíl $\mathrm{Pa}$ ła słéni? aux bake-tr-intr-caus-3erg det bread obl det woman 'He had the bread baked by the woman.' (G's 152, p. 247)

An analysis according to which there is no inner clause obviates the need for the stipulations in (11), which are required on a Clause Union analysis (see Gerdts 1991).

(11) a. The inner clause must be finally intransitive.

b. The inner clause initial 1 , if there is one, must also be the inner clause final 1.

Since passive involves an advancement to 1 , as established above, it is clearly a clause-level syntactic phenomenon. If causativization is characterized as an operation on argument structure, it follows that it cannot be preceded by passive. Causativization of a transitive base on the proposed analysis would involve an operation such as that shown in (12).

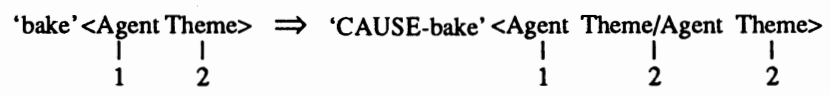

The resulting structure would give rise to a syntactic representation with two initial $2 \mathrm{~s}$, in violation of the STRATAL UNIQUENESS LAW (Perlmutter and Postal 1983), paraphrased in (13).

\section{(13) Stratal Uniqueness Law}

There can be at most one TERM relation $(1,2$, or 3$)$ per stratum.

Under the proposed analysis, then, the very nature of the causative affixation rule precludes transitive and passive bases as input. ${ }^{8}$ 


\section{The Antipassive Construction}

Under the right circumstances, transitive clauses in Halkomelem can be paraphrased with an intransitive structure in which the theme is realized as an oblique rather than as a direct object and a form of intransitive marking is used instead of transitivity marking, as illustrated in (14). ${ }^{9}$

(14)a. ni con q"sl-ət to səplíl

TRANSITIVE

aux 1subj bake-tr det bread

'I baked the bread.'

b. ni can q"כl-əm ?a tº səplíl

ANTIPASSIVE

aux lsubj bake-intr obl det bread

'I baked the bread.' (G's 3a-b, p. 148)

Two arguments can be constructed for analyzing the antipassive construction as involving an alternative linking of the theme with the oblique relation, as shown in Figure 6.

$$
\begin{array}{ccc}
\text { (14b) } & \multicolumn{3}{c}{\text { 'woman' 'bread' }} \\
& \text { Initial: } 1 & 2 \\
\text { Final: Cho } & 1 \\
\text { Revaluation: NO } & \\
\text { (14a) 'woman' 'bread' } & \Rightarrow(14 b) & \text { 'woman' 'bread' } \\
1 & 2 & \text { Obl } \\
& & \\
& \text { Alternative Linking: YES }
\end{array}
$$

Figure 6

The first is based on the fact that antipassive feeds causativization:

$$
\begin{aligned}
& \text { ni cən q"əl-sm-stox" \&a słéni? Po k"0ə səplíl } \\
& \text { aux Isubj bake-intr-caus det woman obl det bread } \\
& \text { 'I had the woman bake the bread.' (G's 76, p. 170) }
\end{aligned}
$$

If the output of the antipassive rule were a syntactic structure, as it would be on a revaluation analysis, the causative rule, which manipulates argument structures, should not be able to follow it. The fact that it can is easily accounted for, however, if antipassive is characterized as a rule that takes as input a word and its argument structure and gives as output another word with a modified argument structure specifically, one that is intransitive by virtue of the fact that the effect of the rule is to override the default linking for themes.

The second argument is based on the observation that (non-eventive) nouns can be formed from antipassivized verbs (Gerdts, personal communication). (16b) shows the antipassivized version of the verb 'sing'.

(16) a. ni con t'ill-t to sti?wi?ał

TRANSITIVE

aux 1 subj sing-tr det hymn

'I sang the hymn.'

b. ni can t'il-əm ?a ta st'i?wi?əł

ANTIPASSIVE

aux l subj sing-intr obl det hymn

'I sang the hymn.'

This form can be used as the base for either a simple noun or an agentive noun, as shown in (17a) and (17b) respectively. 
(17) a. s-t'ilom

NOUN

nom-sing

'song'

b. $x$ "s-t'ilom

AGENTIVE NOUN

ag nom-sing

'singer'

The word formation processes illustrated in (17) are quite common. Although they work on antipassivized verbs, they do not work on verbs with passive morphology. If the output of the antipassive rule is a word rather than a syntactic structure, as on the proposed analysis, it is as expected that this rule can feed word formation processes.

\section{The Applicative Construction}

In general, an animate non-theme argument of a verb in Halkomelem with one of several semantic relations is predictably realized as its direct object, in which case the theme, if there is one, is an oblique. The verb appears with a suffix whose form is determined (at least in part) by the semantic relation of the non-theme argument. The four different kinds of applicatives are illustrated by the examples in (18). 10

$$
\begin{aligned}
& \text { ?i nə?รm-n-əs-əs k" } \theta \text { ə John } \\
& \text { aux go-appl-tr-3erg det John } \\
& \text { 'He went up to John.' (G's 183b, p. 141) } \\
& \text { b. ni } \theta^{\prime} e y ? k^{\text {"w }} \text {-mé?-t-əs k"0a sq"əméy? } \\
& \text { aux startle-appl-tr-3erg det dog } \\
& \text { 'He was startled at the dog.' (G's 3, p. 90) }
\end{aligned}
$$

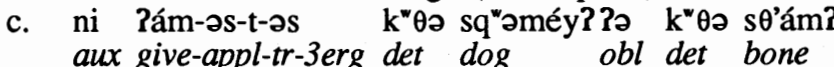

$$
\begin{aligned}
& \text { 'He gave the dog the bone.' (G's } 1, \text { p. 90) }
\end{aligned}
$$

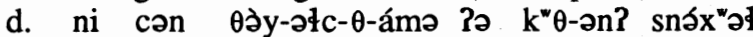

$$
\begin{aligned}
& \text { aux 1subj fix-appl-tr-2obj obl det-2pos canoe } \\
& \text { 'I fixed your canoe for you.' (G's } 21, \text { p. 95) }
\end{aligned}
$$

GOAL 2

CAUSAL 2

RECIPIENT 2

BENEFACTIVE 2

In opposition to the usual RG analysis of applicatives, according to which they involve advancements to 2 from syntactic relations such as 3 , Ben, Goal, etc., I propose that - at least in Halkomelem - they are monostratal constructions, as shown in Figure 7. The applicative suffixes register the presence of a non-theme 2 and, in some cases, a non-canonical linking of a theme argument.

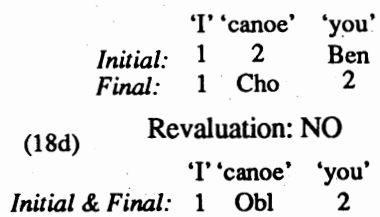

Monostratal: YES

Figure 7 
The reason for entertaining a monostratal analysis is that it provides an explanation for the fact that multiple applicatives are not possible (Gerdts and Whaley in preparation). The kinds of construction indicated in (19) do not occur.

*'I gave-appl-appl the dog the bone for the woman.'

*'Sue went up-appl-appl to John for me.'

It is unclear why there should be such a constraint, if applicative formation is characterized as involving advancements to 2 from various relations and the suffixes register the kind of advancement (3-2, Ben-2, etc.). Since nothing in RG precludes more than two strata, Goal-2 advancement might occur in an earlier stratum than Ben-2 advancement, as shown in (20).

$\begin{array}{cccc}* & \text { Sue John } & \text { me } \\ \text { Initial: } & 1 & \text { Goal } & \text { Ben } \\ & 1 & 2 & \text { Ben } \\ \text { Final: } & 1 & \text { Cho } & 2\end{array}$

The monostratal analysis explains this constraint in conjunction with (13), which guarantees that if (certain) animate non-theme arguments are initial $2 \mathrm{~s}$, there can be only one of these per clause. ${ }^{11}$

\section{SEMANTIC RELATIONS}

\section{A Condition on "Extraction"}

In (pseudo)cleft, question, and relative clause constructions, obliques cannot be directly extracted. Rather, they are extracted via nominalization. That is, the clause of which the focused NP is an oblique dependent is nominalized and embedded in a predicate nominal construction in which the NP in question is the subject. This phenomenon is illustrated by the examples in (21).

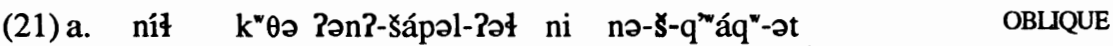
3emph det 2pos-shovel-pst aux 1pos-nom-club-tr INSTRUMENTAL 'It's your shovel that I clubbed him with.' (G's 154, p. 72)

Literally: It's your shovel (that) was my clubbing him (with).


'It's that road that he always ran on.' (G's 155, p. 72)

In the present context the interesting fact about this kind of construction is that a different nominalizing prefix is used if the extracted oblique is a theme. (22a) and (22b) show extracted oblique themes from antipassive and applicative constructions respectively. The nominalizing prefix is $s$ - rather than $\zeta$ -

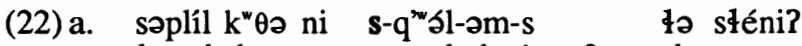

bread det aux nom-bake-intr-3pos det woman

OBLQUE

THEME

'Bread is what the woman baked.' (G's $22 \mathrm{~b}, \mathrm{p} .154)$

b. níł k" $\theta \partial$ púk" ni s-?ám-əs-t-s k"

3emph det book aux nom-give-appl-tr-3pos det

OBLIQUE

swiw?los

boy 'It's a book that he gave the boy.' (G's 56, p. 103)

The condition on extraction of obliques might be formulated in terms of a distinction between obliques and 2 chomeurs (i.e. demoted initial $2 s$ ) if the antipassive 
and applicative constructions involved demotion of an initial 2. Since they do not, as argued above, the condition must be formulated in such a way as to distinguish obliques according to their semantic relations:

$$
\begin{aligned}
& \text { Clauses with extracted obliques are nominalized using } \\
& s \text { - with THEMES, and } \\
& s \text { - otherwise. }
\end{aligned}
$$

\section{A Condition on Reflexivization}

One reflexivization strategy in Halkomelem involves adding the suffix- $\theta \partial t$ to a verb and syntactically suppressing the argument that would otherwise be the direct object. ${ }^{12}$ This strategy cannot be used with the direct objects of applicative verbs, as the following examples show.

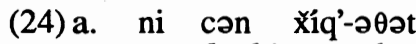

THEME

aux lsubj scratch-refl

'I scratched myself.' (G's 84, p. 113)

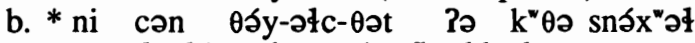
aux 1subj make-appl-refl obl det canoe

'I made myself a canoe.' (G's 87, p. 113)

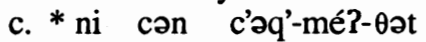

aux 1 subj astonished-appl-refl

'I'm astonished at myself.' (G's 143, p. 130)

*BENEFACTIVE

*CAUSAL

The difference between (24a) and the ungrammatical cases cannot be characterized in terms of whether the suppressed argument is an initial or non-initial 2, given the analysis of applicatives adopted here; rather, it must be characterized in terms of whether the suppressed argument is a theme:

Reflexivization with $-\theta \partial t$ is restricted to THEMES.

\section{Conditions on Applicative Morphology}

Given an analysis of applicatives involving rules sanctioning advancement to 2 from the syntactic relations 3, Ben, Goal, and Causal, the variant forms of the applicative suffix could be accounted for by conditions appealing to particular types of advancement. If, however, there are no advancements, the applicative morphology must be accounted for by conditions that refer directly to what must be characterized as semantic relations, as in (26). ${ }^{13}$

Applicative Verbal Suffixes

a. $-n$ registers a goal initial 2

b. - ałc registers a benefactive initial 2 in a clause with an oblique theme

c. $-2 s$ registers a recipient initial 2 in a clause with an oblique theme

d. -mé? registers a non-theme initial 2 otherwise

\section{CONCLUSION}

In conclusion, Halkomelem evidence adds to the empirical and theoretical sources of motivation discussed in Farrell (1991) for a kind of alternative to classical RG in which semantic relations are explicitly resognized and the role of revaluations and multistratal representations is correspondingly diminished. Internal to Halkomelem such an approach makes possible an analysis that solves several problems. Specifically, explanations become available for: 
- the impossibility of causativization of transitive and passive bases

- the ability of antipassive to feed word formation processes

- the impossibility of multiple applicatives

It is important to emphasize that the kind of theory I am advocating is not simply a variant of current monostratal relational theories, as the possibility of multistratal representations of syntactic relations is not abandoned. The Halkomelem passive construction provides one kind of evidence for such representations. Moreover, there are other languages for which revaluation analyses of causative, antipassive, and applicative constructions are surely to be preferred.

\section{NOTES}

I wish to express my gratitude to Donna Gerdts for producing the thorough and engaging studies of Halkomelem that have made this paper possible and for providing additional information and data.

The following abbreviations are used:

In glosses:

$\begin{array}{lllll}\text { appl applicative } & \text { lnk } & \text { linker } & \text { G } & \text { Gerdts (1988) } \\ \text { aux auxiliary } & \text { intr } & \text { intransitive } & 1 & \text { subject } \\ \text { caus causative } & \text { nom nominalizer } & 2 & \text { direct object } \\ \text { det determiner } & \text { obj obj } & 3 & \text { indirect object } \\ \text { emph emphatic pronoun obl } & \text { oblique } & \text { Ben benefactive } \\ \text { erg ergative } & \text { pos possessive } & \text { Obl oblique } \\ \text { int intransitive } & \text { pst past } & \text { Cho chomeur } \\ \text { l.c. limited control } & \text { tr } & \text { transitive } & & \\ 1 & \text { first person } & 2 & \text { second person } & \end{array}$

Interlinear glosses in the Halkomelem examples cited have in some cases been changed from the source slightly due to the reanalysis.

1 Although no explicit allowance is made for alternative linking in classical $\mathrm{RG}$, there have been analyses in which this device is employed - notably Rosen's (1990) analysis of Southern Tiwa indirect objects and Aissen's (1983) analysis of benefactives in Tzotzil.

2 Actually, I analyze the towel as a final oblique, as I do not recognize "chomeur" as a primitive relation. The motivation for the kind of analysis shown in Figure 3 is that it makes possible the best account of the interaction of dative shift and passive (Farrell 1991, Ch. 4). Other kinds of motivation are given for a similar approach to this kind of construction in other languages. See Farrell (1991, Ch. 3) on the claim that something like both conditions in (3) are needed.

3 Gerdts attributes this observation to unpublished work by Thomas Hukari. Davis (1980) discusses the phenomenon in Sliammon, for which the condition is somewhat different.

4 That the "raisee" in this construction is the final 2 of the main clause can be seen quite clearly when this NP is first or second person. The main clause verb shows object agreement with the raisee.

${ }^{5}$ I assume here the analysis of passive clauses presented in Gerdts (1989a), according to which passive clauses with a first or second person logical object which can be a raisee - are PERSONAL passives. The IMPERSONAL passive analysis of this kind of clause presented in Gerdts (1988) creates a problem for (8). The un- 
usual thing about passive clauses in Halkomelem with a first or second person logical object is that this argument determines a kind of object agreement. Under the assumption that object agreement is determined by a 2 in a transitive stratum, a PERSONAL passive analysis of this kind of clause is thoroughly reasonable. Indeed, the fact that object agreement occurs provides a piece of evidence for a revaluation analysis.

6 The causative suffix is generally analyzed as a kind of "transitivity" marking (in addition to Gerdts (1988), see Galloway (1977)). It is realized as -stox" when the object is third person, as in (9b); otherwise it is -st and is followed by object agreement. Galloway analyzes $-2 x^{*}$, which also appears with third person objects in clauses with so-called "limited control" transitivity marking, as a third person agreement marker.

7 This analysis of Halkomelem causatives differs significantly from that suggested in Farrell (1991, Ch. 2), which I now believe to be wrong.

8 The assumption here is that themes are linked to the initial 2 relation by default. Nothing, in principle, precludes the possibility that the default linking for themes might be overridden by an alternative linking rule. The causative rule, however, is not characterized as one that has this effect.

9 Depending on the particular verb, an alternative suffix or no suffix at all could be used in the antipassive construction.

10 There is no alternative paraphrase in the case of applicatives with a theme (as in (18c-d)). If a causal or goal argument is inanimate it must be realized as an oblique, in which case the applicative suffix is not used. Although it is apparently not the preferred strategy, it is possible for an animate goal to be realized as an oblique in a construction without applicative morphology.

11 An analysis of applicatives according to which the non-theme is an initial 3 that obligatorily advances to 2 (along the lines of the analysis in Figure 3 ) would also explain why there can be no multiple applicatives. That is, the explanation would be that (13) precludes a structure with more than one initial 3 . The proposed analysis obviates the need for a rule of 3-2 advancement; however, it requires an alternative linking rule for themes in applicative clauses - the effects of which would follow from an advancement analysis, under the assumption that an advancement to 2 would necessarily cause the initial 2 to demote to chomeur (or oblique, as in Farrell (1991)). Although they would require some reformulation, the arguments in section 3 would remain valid under the alternative 3-2 advancement analysis of applicatives.

12 Since reflexivized verbs can be causativized, it must be assumed, given the analysis of causativization proposed here, that reflexivization is an operation on argument structure - specifically, one that has as a result that the theme is not linked to the initial 2 relation. If this assumption is correct, the constraint on reflexivization must be stated in terms of the notion theme independently of whether the alternative analysis of applicatives considered in note 11 is adopted. This assumption concerning reflexivization appears unproblematic, unless the reflexive suffix is analyzed (as in Gerdts 1989b) as consisting of a transitive marker $t$ - plus a reflexive morpheme -sut and transitivity marking is analyzed as registering a transitive stratum. I assume that it is possible to treat the reflexive suffix as a single morpheme synchronically (as, for example, in Gerdts 1988 and Galloway 1977). Such an analysis obviates the need for an abstract underlying representation and the associated morphophonemic rules. 
13 These rules are formulated in such a way as to account for the fact that -mé? is used in cases where a benefactive argument is added to a basically intransitive verb (Gerdts, personal communication).

\section{REFERENCES}

Aissen, Judith (1983) "Indirect Object Advancement in Tzotzil," in Perlmutter (1983).

Aissen, Judith and David M. Perlmutter (1983) "Clause Reduction in Spanish," in Perlmutter (1983).

Davis, John H. (1980) "Passive in Sliammon," Proceedings of the Sixth Annual Meeting of the Berkeley Linguistics Society, Universtiy of California, Berkeley.

Farrell, Patrick (1991) Thematic Relations, Relational Networks, and Multistratal Representations, Doctoral dissertation, University of California, San Diego.

Galloway, Brent D. (1977) A Grammar of Chilliwack Halkomelem, Doctoral dissertation, University of California, Berkeley.

Gerdts, Donna B. (1988) Object and Absolutive in Halkomelem Salish, Garland, New York. Doctoral dissertation, University of California, San Diego, 1981.

Gerdts, Donna B. (1989a) "Object Agreement in the Halkomelem Salish Passive: A Morphological Explanation," in General and Amerindian Ethnolinguistics: In Remembrance of Stanley Newman, Mary Ritchie Key and Henry M. Hoenigswald (eds.), Mouton de Gruyter, Berlin.

Gerdts, Donna B. (1989b) "Relational Parameters of Reflexives: The Halkomelem Evidence," in Theoretical Perspectives on Native American Languages, Donna B. Gerdts and Karen Michelson (eds.), State University of New York Press, Albany.

Gerdts, Donna B. (1991) "Unaccusative Mismatches in Halkomelem Salish," International Journal of American Linguistics 57, 230-250.

Gerdts, Donna B. and Lindsay Whaley (in preparation) "Kinyarwanda Multiple Applicatives and the 2-AEX," Simon Fraser University and SUNY Buffalo.

Gibson, Jeanne D. and Eduardo P. Raposo (1986) "Clause Union, the Stratal Uniqueness Law, and the Chomeur Relation," Natural Language and Linguistic Theory 4, 295-331.

Perlmutter, David M. (1980) "Relational Grammar," in Syntax and Semantics 13: Current Approaches to Syntax, Edith Moravcsik and Jessica Wirth (ed.), Academic Press, New York.

Perlmutter, David M. (ed.) (1983) Studies in Relational Grammar 1, University of Chicago Press, Chicago.

Perlmutter, David M. and Paul M. Postal (1983) "Some Proposed Laws of Basic Clause Structure," in Perlmutter (1983).

Rosen, Carol (1990) "Rethinking Southern Tiwa: The Geometry of a TripleAgreement Language," Language 66, 669-713. 